\title{
Exposer
}

\section{Christophe Didier}

\section{(2) OpenEdition}

Journals

Édition électronique

URL : https://journals.openedition.org/rbnu/3423

DOI : $10.4000 /$ rbnu.3423

ISSN : 2679-6104

\section{Éditeur}

Bibliothèque nationale et universitaire de Strasbourg

\section{Édition imprimée}

Date de publication : 1 mai 2011

Pagination : 6-7

ISSN : 2109-2761

\section{Référence électronique}

Christophe Didier, «Exposer », La Revue de la BNU [En ligne], 3 | 2011, mis en ligne le 01 mai 2011, consulté le 09 août 2021. URL : http://journals.openedition.org/rbnu/3423 ; DOI : https://doi.org/ $10.4000 /$ rbnu.3423

\section{(c) (i) (3)(2)}

La Revue de la BNU est mise à disposition selon les termes de la Licence Creative Commons Attribution - Pas d'Utilisation Commerciale - Partage dans les Mêmes Conditions 4.0 International. 


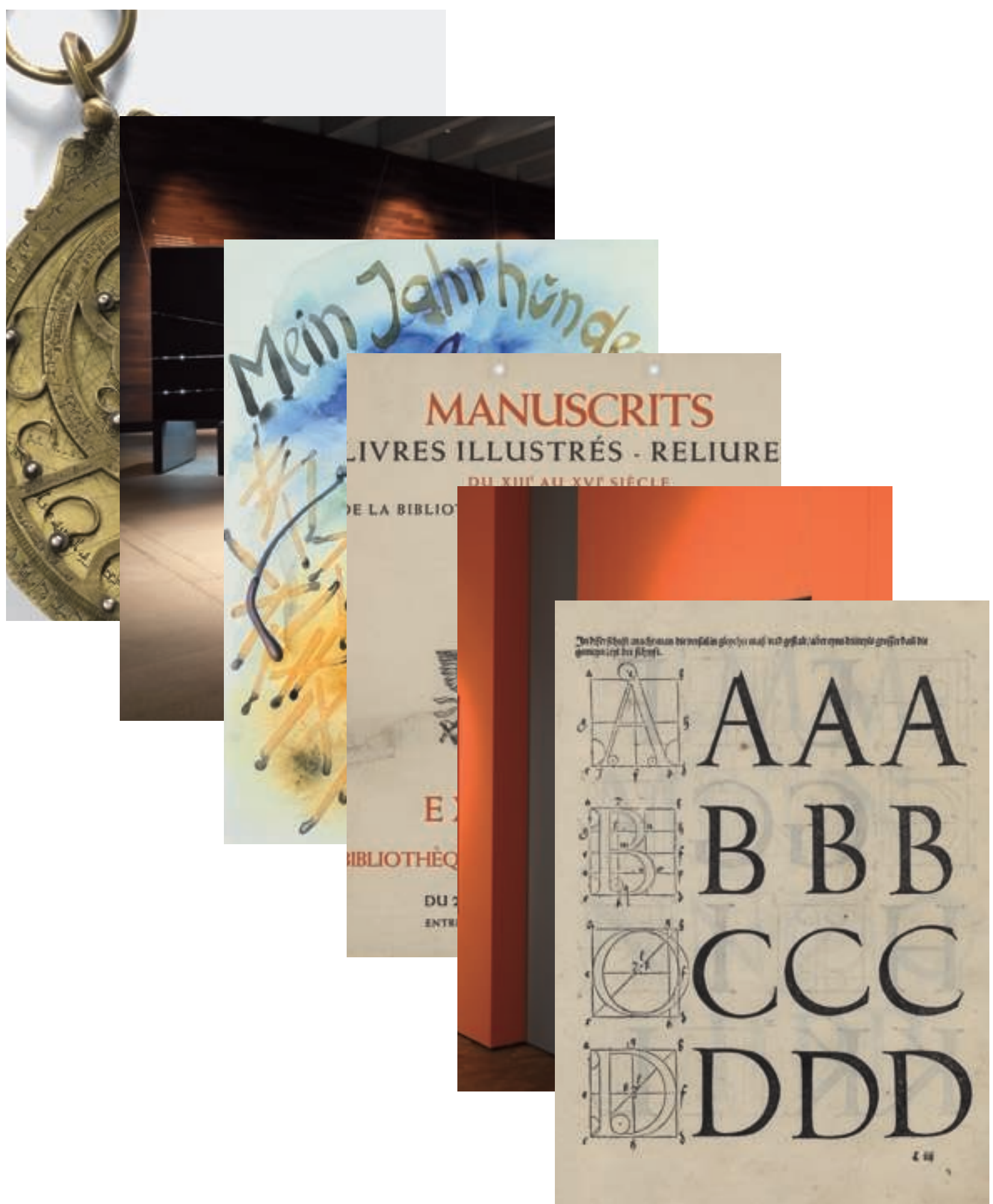




\section{LE DOSSIER Exposer}

Avec l'avènement du tourisme de masse, l'exposition est devenue une activité de loisir qui se répand dans des couches toujours plus importantes de la population. Il est convenu aujourd'hui, pour un Français qui se veut cultivé, non seulement de " faire " les grandes expositions parisiennes, mais encore de prévoir suffisamment à l'avance les réservations de train, d'hôtel et de ticket d'entrée qui s'imposent, sous peine de se retrouver dans des trains bondés ou face à des files d'attente de plusieurs centaines de mètres parfois - bref, visiter une exposition médiatisée n'est plus un geste insouciant ou improvisé mais relève de l'organisation d'un loisir culturel.

Est-ce un bien ? Est-ce un mal ? La Revue de la BNU n'entend pas lancer la polémique... Par contre, le phénomène social de l'exposition, par l'extension qu'il donne à son sujet, oblige à le considérer aujourd'hui en des termes nouveaux : si l'exposition classique (rétrospective d'artiste, présentation de collections muséales, grands thèmes culturels) a peu changé depuis la fin des années 70, on constate aujourd'hui qu'on expose dans des lieux de plus en plus divers et qu'on n'hésite pas à confier à des établissements dont ce n'est pas forcément la mission première (comme par exemple des bibliothèques...) la tâche de mettre en scène des sujets qui a priori ne s'y prêtent pas : ainsi pour ce numéro les jeux vidéo, le fait littéraire ou bien encore l'influence de la pensée d'Hitler sur la société allemande de son temps.

Comment faire pour exposer dans des lieux inhabituels ? Comment traiter les sujets retors (par exemple, bien exposer un livre...) ? Comment rendre visibles des processus intellectuels (ou comment les suggérer suffisamment précisément pour qu'un spectateur ait l'impression d'avoir compris, ou appris, parce qu'il aura vu) ? Comment, pour le redire en un mot, réussit-on à exposer un sujet qui a priori ne s'y prête pas ? Ce sont des questions qui se posent à toute bibliothèque qui tente de mettre sur pied une politique d'action culturelle qui soit aussi un moyen de valorisation de ses collections. Plus généralement, ces questions finissent par toucher tous les établissements susceptibles de répondre à la formidable demande d'exposition qui est aujourd'hui celle du " grand public cultivé ", et qui doivent s'adapter aux critères scénographiques indispensables pour réussir ce qui reste toujours un pari, voire une gageure. A travers des exemples qui vont de l'exposition du pixel à celle du signe calligraphique, à travers des expériences d'artistes, d'écrivains et de professionnels de la culture, La Revue de la BNU souhaite à sa façon apporter sa contribution à une réflexion sur un phénomène culturel désormais lui aussi mondialisé.

\section{Christophe Didier}

